\title{
Estado e sociedade e as reconfigurações do direito à saúde
}

\author{
State and society and the new configurations \\ of the right to health
}

\footnotetext{
1 Departamento de M edicina Preventiva da Faculdade de M edicina da USP e CEDEC.

Rua dos Franceses 498, 411F Bela Vista, 01329-900 São Paulo SP. amelcohn@uol.com.br
}

Abstract The present essay in which the author seeks to reintroduce some of the main discussions within the social sciences literature on the relationship among state and ci vil society, and which can contribute for a reflection about social involvement in health policies. In this regard, the focus is on the political dimension proper of this relationship, putting aside- despite its relevance - society's participation on the provision of health services. The main axes of the analysis are the social and political implications in choosing the poverty or inequality perspective; social movements and social rights; and the state/society relationship in a context lacking basic rights. Attention is given to the institutionalization of citizenship within the perspective of justice and social equity in face of the diversity and plurality of contemporary societies, especially the Brazilian, considering the huge social inequalities characterizing it. The last session briefly reviews some of the main features of social participation in $\mathrm{H}$ ealth Councils present in several analyses of this theme, without pursuing an evaluation of this literature regarding its theoretical or methodological features.

Key words Social movements and social rights, Social participation and the public sphere, Establishment of social rights and the new social identities
Resumo Este ensaio resgata algumas das princi pais discussões travadas na literatura das ciências sociais sobre as relações entre Estado, sociedade civil e participação social nas políticas de saúde. 0 recorte adotado é a dimensão política propriamente dita, deixando-se à parte - embora seja igualmente rel evante - a participação da sociedade na provisão e produção de serviços de saúde. Os principais ei xos de análise são as implicações sociais e políticas da opção pela perspectiva da pobreza ou da desigualdade; os movimentos sociais e os direitos sociais; ea relação Estado/sociedade num contexto de destituição de direitos. Privilegia-sea ótica da instituição da cidadania da perspectiva da justiça e da eqüidade social frente à diversidade e ao pluralismo que marcam as sociedades contemporâneas, em especial a brasileira, dadas as enormes desigualdades sociais que a caracterizam. A última sessão retoma de forma sucinta alguns dos principais traços que vêm marcando a experiência da participação social nos Consel hos de Saúde apontados pelas numerosas análises a respeito, sem no entanto se fazer um balanço dessa literatura quanto aos marcos teóricos e metodológi cos aí presentes. Palavras-chave M ovimentos sociais e direitos sociais, Participação social e esfera pública, A constituição de direitos sociais e as novas identidades sociais 
Debruçar-se sobre a nossa real idade social no atual contexto da globalização constitui uma tarefa das mais complexas, até porque de imediato se é tentado pela negação dos clássicos paradigmas das ciências sociais que vêm norteando nossas análises. No entanto, talvez 0 maior desafio consista exatamente em merguIhar nessa nova realidade, que afinal não rompe de forma radical com seu processo histórico, mas fazê-lo "com os ol hos voltados para o futuro" como alertava o mestre Florestan Fernandes, e portanto criticamente deslindar os limites que os velhos model os e conceitos clássicos das ciências sociais antepõem frente a essa nova complexidade social.

A preocupação que norteia este texto não reside em discutir se existe ou não na atualidade uma crise de paradigmas nas ciências sociais, mas tão somente apontar o que parece caracterizar a realidade social atual frente às análises que até há bem pouco tempo vinham sendo realizadas sobre ela. A referência mais imediata será sempre a realidade brasileira, ou quando muito a dos "países emergentes", e da perspectiva, uma vez mais recorrendo ao mestre Florestan, intransigente quanto à defesa dos valores democráticos e igual itários que vêm sendo tão desacreditados na atualidade diante da mística da eficiência do mercado versus a ineficiência (igualmente atribuída) intrínseca do Estado.

Dessa perspectiva, de imediato ganham relevo alguns dos principais fenômenos dessa "nova" conjuntura, os quais deveriam constituir, de certa forma, a agenda de preocupações dos cientistas sociais. 0 primeiro deles diz respeito a buscar compreender as novas configurações de exclusão social presentes em nossa sociedade: se não mais prevalece o padrão de integração social via trabalho, e cada vez mais comprovada a impossibilidade - reconhecida atual mente até pelas agências multilaterais - de se estabelecer um padrão de integração social via mercado, resta-nos então buscar detectar os novos padrões de contratos e de solidariedade social que vêm emergindo. 0 segundo deles diz respeito a buscar identificar, sem divorciar o nível macro do nível micro de análise, os novos atores e sujeitos sociais presentes na realidade social, como ainda as novas configurações de sociabilidade que vêm emergindo no tecido social. 0 terceiro deles, conseqüência lógica dos anteriores, diz respeito a buscar identificar e compreender, nas sociedades contemporâneas, os novos espaços de construção de identidades sociais e de direitos e seu reverso, de desconstrução dessas identida- des e de desregulação desses direitos - , vale dizer, a constituição e dinâmica dos novos espaços da política, que não aqueles tradicionalmente reconhecidos. E o quarto deles diz respeito ao desafio de se buscar entender, e para tanto desenvolver instrumental analítico adequado, o Estado e os processos de formulação e implementação de políticas públicas que pratica tendo em vista a nova configuração da sociedade.

Claro que os pontos relacionados acima não poderiam jamais constituir a estrutura de um artigo, mesmo que seu autor fosse capaz de desenvolvê-los com competência, o que não é o caso. Assim, pontuá-los teve por objetivo exatamente o oposto: diante da amplitude e da complexidade que a realidade das sociedades contemporâneas nos impõe, realçar o caráter absolutamente exploratório das questões que serão aqui abordadas, e sempre tendo por referência, explícita ou implícita, a realidade brasileira.

\section{D a pobreza à desigualdade: implicações sociais e políticas}

A questão da pobreza vem sendo objeto freqüente de estudos teórico-conceituais e empíricos por parte dos cientistas sociais. E da mesma forma que se multiplicam estudos a respeito, a polêmica entre os especialistas também se torna acalorada, sobretudo repondo a velha polêmica entreos "quantitativistas" eos "qualitativistas". Por outro lado, há que se reconhecer que a retomada do tema da pobreza na agenda dos debates de natureza mais pública, sobretudo nos países emergentes, em grande medida foi promovida pelas propostas minimalistas das agências multilaterais, em consonância com 0 ideário do Consenso de Washington.

No entanto, definir e problematizar a questão da pobreza, a par da dificuldade de se ter clareza sobre os matizes ideológicos que el a traz sempre consigo, coloca em xeque toda uma série de preceitos e parâmetros tradicionais com os quais os cientistas sociais vêm se debruçando sobre a realidade social. 0 mais evidente, entre eles, diz respeito às diferenças hierárquicas e da condição social entre os indivíduos que compõem a sociedade: castas, estamentos e classes sociais, sobretudo no que se refere a esta última. Em outros termos, trata-se fundamentalmente de buscar sempre os mecanismos de coesão social em realidades diferenciadas e crivadas por tal divisão de interesses que, no limite, levariam à ruptura da ordem social vigente. 
As distintas formas de inserção dos indivíduos nas sociedades modernas ocidentais eram até muito recentemente analisadas sob a ótica das classes sociais, sobretudo a partir das vertentes weberiana e marxista, uma privilegiando a classificação dos indivíduos por acesso a bens materiais e imateriais, e a outra privilegiando a inserção dos indivíduos na produção. Em ambas, no entanto, o que prevalece, e aqui é o que importa, é o trabalho como fator social fundamental para a inserção social dos indivíduos, eque assim assume, como nos aponta offe (1989), a condição de um conceito sociológico-chave. É a partir dele que se explica a coesão social como um valor em si ou as forças de superação daquelas realidades sociais.

No entanto, a questão que se nos apresenta hoje em dia é exatamente a da ausência do trabalho, nas sociedades contemporâneas, como fator de inserção social dos indivíduos, e portanto de explicação das diferenças sociais entre eles. Sem o contraponto do trabalho, volta-se agora para a renda: a questão dos distintos graus de inserção social tende então a ser pautada quase que exclusivamente por níveis de renda, portanto pela capacidade de os indivíduos no âmbito da esfera privada mostrarem-se aptos ou não - para proverem suas necessidades sociais básicas. As diferenças sociais passam agora a ser definidas como níveis de renda, e aqueles grupos que percebem um valor mensal abaixo de um determinado valor arbitrariamente definido são classificados como "pobres". E a partir daí, no sentido descendente, classificam-se os "miseráveis", ou "indigentes", que constituem aqueles que sequer são capazes de garantir por conta própria níveis mínimos de sobrevivência alimentar.

$M$ as ao mesmo tempo que se processa esse deslocamento das "classes" para "grupos de renda", verifica-se a perda das identidades sociais desses sujeitos, uma vez que, ao perderem aquela sua condição, passam a ser objeto de intervenção do Estado por meio de políticas públicas neles focalizadas. Dessa perspectiva, a condição de pobreza não obedece a um gradiente comparativo de acesso à riqueza, embora se vincule indiretamente ao acesso a consumo de determinados bens e serviços, o que passa a servir de parâmetro para a definição das linhas de pobreza.

Já a perspectiva da desigualdade social implica necessariamente a posição relativa dos distintos segmentos sociais entre si, uma vez que o fator nuclear reside na distribuição compara- tiva dos indivíduos em gradientes distintos de acesso ao consumo a determinados bens e serviços. N esses termos, pobreza e indigência, por exemplo, são definidas a partir de parâmetros relativos e não absolutos, possibilitando que se retome a perspectiva dialética da sua superação, ao contrário do caso anterior, que circunscreve a pobreza ao círculo restrito de ações que "aliviem" a condição imediata de vida desses grupos sociais, tal como analisam M endonça e Souto (2001)

A matriz da pobreza, portanto, é radicalmente distinta da matriz da desigualdade social, tanto no que diz respeito às análises que daí se derivam sobre a própria sociedade quanto no que diz respeito, consequentemente, às formas de se analisar como ela as enfrenta. Restringindo-se à primeira dessas dimensões, ganha destaque a questão dos sujeitos sociais e o lugar que ocupam nas sociedades contemporâneas, para o que a questão dos movimentos sociais e dos novos sujeitos sociais, ou dos segmentos organizados da sociedade, passa a ser de especial interesse.

\section{Movimentos sociais e direitos sociais}

Os movimentos sociais se caracterizam por se constituírem em "novos" sujeitos coletivos no cenário político em distintas e diferenciadas are nas e espaços que não aqueles tradicionalmente definidos pela concepção liberal clássica de democracia. Por outro lado, constituem igualmente sintomas de conflitos presentes na própria sociedade na medida em que se caracterizam por um forte traço reivindicativo na luta por conquistas na efetivação de demandas sociais, vale dizer, dos direitos sociais. A partir de sua especificidade e, nesse sentido, de sua particularidade, reivindicam direitos sociais que implicam a igualdade de direitos associada ao direito à diferença, e portanto à justiça social. É a partir dessa intrincada confluência que se apresentam duas questões relativas à sua representatividade quando vitoriosos na conquista de suas demandas - a sua origem como representação de interesses de determinados grupos sociais e a natureza de sua própria legitimidade.

No decorrer dos anos 70 e 80, quando se verifica um boom da produção acadêmica sobre movimentos sociais, fenômeno então emergente nas sociedades, quase sempre a eles eram atribuídas duas qualidades: sua espontaneidade eseu senso dejustiça, na medida em que suas 
demandas eram decididas entre pares iguais, $e$ sua independência com relação às elites, como analisa Cardoso (1983). N essa mesma época Alain Touraine (1983), por exemplo, atribuía aos movimentos sociais a condição de serem fatos "portadores de futuro". N ote-se, no entanto, que a discussão em torno do surgimento desses "novos sujeitos sociais" é regida, fundamentalmente, por duas ordens de preocupação: de um lado, pela dimensão do controle público da gestão do Estado e, de outro, pela dimensão das transformações na manifestação dos conflitos sociais e seu impacto sobre o sistema político.

No primeiro caso - a dimensão do controle público da gestão do Estado - , o fio condutor dos debates sobre os movimentos sociais reside no argumento de que nas sociedades pós-industriais a gestão e o controle público tendem a se aproximar porque os conflitos sociais tendem a se generalizar por toda a rede societal, verificando-se uma reaproximação entre a base social das ações coletivas e suas formas de ação. No segundo caso - a dimensão de seu impacto sobre o sistema político até então vigente no que diz respeito aos canais e mecanismos de representação de interesses - essas novas práticas sociais não significariam o enfraquecimento do sistema político na medida em que a emergência e generalização dos movimentos sociais tomam forma exatamente no âmbito dos próprios problemas sociais, enão no da coletividade política. Ambas as dimensões se fazem presentes, por exemplo, na fundamentação da proposta dos Consel hos de Saúde e, posteriormente, nas análises sobre seu funcionamento e significado.

0 desenvolvimento da reflexão e dos estudos sobre os movimentos sociais cada vez mais se consolida - mesmo quando a questão da globalização ainda não emerge de forma candente na literatura produzida pelos cientistas sociais - na direção da evidência, nas sociedades contemporâneas, de uma transformação dos conflitos sociais: estes passam a ocorrer não mais em nome do cidadão ou do trabal hador, conduzindo a grandes lutas reivindicativas contra um aparelho de dominação que rege cada vez mais o conjunto da soci edade orientando-a para um certo tipo de desenvolvimento, mas em nome da coletividade. 0 que de imediato remete à necessidade de se enfrentar o desafio de diferenciar entre aqueles conflitos sociais de natureza estrutural e aqueles ligados à mudança. Em resumo, esses novos fenômenos sociais tendem a não ser mais interpretados como forças de oposição na construção de um novo poder, mas como forças de oposição que se definem como tal sem trazer em si mesmas um novo modelo de sociedade e o germe de um novo Estado.

Daí derivam várias propostas de definições dos movimentos sociais entendidos como sujeitos sociais: como um sistema de ação associando orientações e significados plurais; como formas de ação coletiva baseada na solidariedade desenvolvendo conflito erompendo os limites do sistema em que a própria ação ocorre; como suas características residindo na convivência do conflito (relação entre atores opostos que disputam entre si pelos mesmos objetivos) com a solidariedade (partilhar uma identidade social); ou como representando a possibilidade de se romperem os limites do sistema estabelecido no âmbito de um espectro de variações ditado por uma estrutura já existente (M elucci, 1989).

No entanto, independentemente da diversidade de compreensão sobre os movimentos sociais como fenômeno social, a referência sempre presente nos mais diversos textos sobre o tema consisteno fato de eles se diferenciarem das formas clássicas de organização dos trabalhadores, em sindicatos e centrais sindicais, como organismos centralizados de representação de interesses, e que reafirmam sua ação de representação associada a um padrão de intervenção na esfera pública (para além dos históricos vínculos orgânicos com o Estado) através dos canais estabelecidos pelos sistemas políticos representativos. Haja vista, por exemplo, a sua participação no núcleo dos processos de regulação econômica e social que fundaram as bases do welfare state na Europa, o que se deu, diga-se de passagem, de forma radicalmente distinta nos casos brasileiro e latino-americano quando da constituição dos respectivos sistemas de proteção social, dado que na região os sindicatos se constituíram sob a tutela do Estado.

$M$ ais do que se diferenciarem das formas clássicas de organização dos trabalhadores com o avançar da década de 1980, os movimentos sociais ganham intensidade, revelando-se uma forma de organização da sociedade que acompanha as mudanças próprias dos processos de globalização da economia e da reestruturação produtiva que lhe são próprios, deslocando o trabal ho como elemento central de inserção dos indivíduos na sociedade. Por outro lado, esse processo é reafirmado pelo fato de no geral os movimentos sociais, sobretudo na América Latina e no Brasil, estarem vinculados à situação 
de carência em que se encontram os indivíduos neles engajados. N outros termos, é a situação de carência, como um processo subjetivo e individual que compreende escolhas entre carências diversas, que acaba sendo o fator nuclear que de um modo geral provoca a organização de determinados grupos em movimentos sociais, eque acaba por associá-los aos critérios de legitimidade política. Portanto, é a partir das distintas situações de carências que são mediadas as formas como esses grupos sociais vêem a si mesmos e aos demais, bem como as maneiras como imprimem significado ao fim ético do Estado.

Em conseqüência, os movimentos sociais tendem a mobilizar e organizar seus membros na busca de fins materiais e não materiais que consideram injustamente negados pelo Estado e suas instituições, buscando conquistar maior autodeterminação no interior do próprio Estado, ou evitando-o radicalmente, a ele se contrapondo. M as de uma maneira ou de outra, acabam por se revelar como constituintes de novas formas de sociabilidade que apontam para a transformação da sociedade civil, ampliandoa e redefinido-a no interior das próprias regras do jogo do poder político. Essa transformação ocorre, no entanto, num contexto em que entram em cena dois outros fatores: de um lado, 0 progressivo debilitamento da soberania do Estado para a definição de suas políticas nacionais, aumentando o descompasso entre as políticas econômicas e sociais que implementa, continuando estas últimas a terem como referência o Estado nacional, enquanto aquelas passam a ser crescentemente determinadas pela economia global. De outro lado, aos movimentos sociais que emergem e se estruturam na América Latina a partir dos anos 70, e que têm como objetivo a luta pela conquista de determinados direitos junto ao Estado nacional, acrescentam-se outros no período mais recente, tendo como referência não a sociedade local mas a global, elegendo organizações de âmbito global como arena de atuação e sujeitos de interlocução.

Destaque-se, porém, que o fato de no geral os movimentos sociais estarem vinculados à noção de carência, que se transforma no alvo de suas ações reivindicativas, faz com que na condição de sujeitos coletivos eles sejam exatamente os "excluídos", os "carentes" e os "discriminados". E a partir dessa condição suas ações reivindicativas tendem a se traduzir em conquistas não necessariamente de direitos - que implicam a prestação pelo Estado de serviços legítimos para cidadãos livres e iguais perante a lei
-, mas em benesses concedidas pelo Estado. Estas, embora não menos legítimas, assumem no seu conjunto o significado de privilégios a determinadas clientelas que foram capazes de impor sua demanda de modo específico, e nesse sentido particular, reforçando nessa dinâmica paradoxal a tradição histórica brasileira, por exemplo, de expansão não universal dos direitos, conforme já registrado na análise clássica de Santos (1979).

Em conseqüência, quando se pensa nas implicações sociais e políticas da opção pela pobreza ou pela desigual dade como perspectiva de anál ise - e consequentemente de formulação de políticas -, o que está em jogo é exatamente a opção de se enfrentar ou não a questão proposta por M arshall (1963) já no início dos anos 60: a da tensão irredutível, no que diz respeito aos direitos sociais, entre o princípio da igualdade que os postula e as desigualdades inerentes ao mercado. Essa tensão, no entanto, à época compunha uma realidade em que, como aponta Santos (1997), o paradigma capitalista caracterizava-se pela contradição entre os princípios da emancipação, apontando para a igualdade e a integração social, e o da regulação, gerindo os processos de desigualdade e exclusão social produzidos pelo próprio desenvolvimento capitalista; já na atual idade, essa contradição deixa de ser criativa, constituindo-se a emancipação não mais no outro da regulação, mas no seu duplo, gerando uma crise nos padrões de regulação e de gestão controlada do sistema de desi gual dade e de exclusão social. Isso na medida exata em que se verifica nas sociedades contemporâneas o mercado transformando-se no fator central de articulação e organização da sociedade, rompendo-se os contratos sociais de solidariedade que lhe eram próprios e passando a prevalecer os princípios e as regras da esfera privada sobre aquel es inerentes à esfera pública. E, como conseqüência, perde-se a concepção do direito de cidadania, que passa a ser subsumida pela de direito do consumidor.

\section{Relação Estado-sociedade num contexto de destituição dos direitos}

O fenômeno da desigual dade social ocorre de maneira até certo ponto distinta nos países centrais e nos periféricos. Enquanto nos primeiros o processo de maior fragmentação da diferenciação social faz com que se passe de uma diferenciação "dura" para uma "fluida", dificilmente 
passível de uma codificação precisa e redundando numa maior "opacidade social", conforme analisado por Fitoussi e Rosanvallon (1996), nos periféricos essa fragmentação retoma o veIho tema da marginalidade social dos anos 70 , referida portanto fundamentalmente ao trabaIho; e atualmente, se configurando na exclusão pura e simples de uma parcela crescente da população (Zaluar, 1997) não passível de ser globalizada, o que demanda que se mergulhe na questão das configurações atuais da sociedade civil.

Assim, não é por acaso que se verifica no período recente o ressurgimento do tema da sociedade civil entre os cientistas sociais. Afirma Arato (1995): 0 notável êxito histórico da recuperação do conceito [de sociedade civil] ... deveuse ao fato de que ele prenunciava uma nova estratégia dualista, radical, reformista ou revolucionária, de transformação da ditadura, observada primeiramente no Leste europeu e, logo depois, na América Latina, para a qual convergiu e ofereceu os el ementos de uma compreensão intelectual. Essa estratégia baseava-se na organização autônoma da soci edade, na reconstrução de laços sociais fora do Estado autoritário e na concepção de uma esfera pública independente e separada de toda forma de comunicação oficial, estatal ou controlada pelos partidos.

M erecem destaque aqui três elementos apontados pelo autor: 0 caráter autônomo da organização da sociedade, a reconstrução de laços sociais fora do Estado, e uma esfera pública independente e separada de toda forma de comunicação oficial. Esses três elementos, sabidamente indissociáveis da totalidade à qual pertencem, permitem retomar um dos problemas centrais na relação entre esses novos sujeitos sociais em seus processos de criação de suas identidades eo Estado, qual seja, o lugar que ocupam hoje, que grupos sociais representam equal a fonte de sua legitimidade, a definição de seus principais interlocutores, e a natureza de suas demandas.

Talvez essa perspectiva constitua uma alternativa interessante para se tentar sistematizar as abordagens que vêm sendo propostas sobre a rearticulação das relações Estado-sociedade. Uma delas, denominada por Grau (1996) de neoconservadora, preconiza a ampliação da esfera de ação da sociedade civil a partir da negação do Estado, dentro das normas institucionais vigentes. N este caso, como aponta Lechner (1981), a conseqüência seria uma desmobilização e uma despolitização sociais decorrentes do próprio fortalecimento da sociedade civil. Já uma outra abordagem aponta exatamente na direção oposta: a busca da ampliação da democracia política e social como diretriz para a rearticulação das relações entre Estado e sociedade civil, colocando no centro do debate a questão da igualdade, da justiça e da solidariedade, num processo de ampliação e consolidação da esfera pública.

Enquanto a primeira vertente de certa forma recusa a característica inerente ao Estado que vem a ser a política, constituindo a desmobilização e a despolitização do social a contrapartida do fortalecimento da sociedade civil e da retração das instituições políticas, a segunda vertente apontaria para a ampliação da democracia política e social como instrumento de rearticulação das relações Estado-sociedade civil, e tendo como eixo exatamente o fortalecimento da dimensão pública da vida social no próprio processo daquela rearticulação, conforme assinalado por Grau (1996).

No entanto, a atribuição de prioridade à dimensão da esfera pública confronta-se uma vez mais com um contexto social caracterizado exatamente pela fragmentação da ação coletiva, em grande parte decorrente da própria pulverização social e da falência dos mecanismos de regulação social até então prevalecentes, bem como pelo surgimento das novas formas de representação social dos interesses dos distintos segmentos e grupos sociais. Por outro lado, a atribuição dessa prioridade significa o reconhecimento não só da existência de uma tensão crescente entre Estado e sociedade, mas também do fato de que a esfera estatal não se caracteriza mais como sendo o monopólio do espaço de existência da esfera pública. A conseqüência lógica é a necessidade de que o próprio Estado passe a incorporar de forma ativa a sociedade civil, conferindo espaços próprios às modalidades emergentes de solidariedade social. Isso porque, dado que se o estatal eo público não se confundem, o fortalecimento da sociedade civil tem que se tornar solidário com a construção da democracia e da cidadania, implicando a própria democratização do Estado. É nessa rearticulação das relações do Estado com a sociedade civil que passa a residir a possibilidade de emergência das condições para a recriação da cidadania política e a expansão da ci dadania social, como aponta Grau (1996) em seu texto.

Dessa perspectiva ganha relevância a proposta de Cohen e Arato (1992) de se distinguir entre sociedade civil como movimento e sociedade civil como instituição, a primeira confi- 
gurando-se como uma sociedade civil constituinte, que cria a segunda, sua versão constituída e institucionalizada, em que pese o fato de, como alertam os autores, a relação temporal entre ambas nem sempre ser evidente. Também é oportuno que se registre a proposta dos autores de se distinguir, para fins analíticos, entre uma sociedade econômica, caracterizada por relações ditadas pelas formas de propriedade e associações de cunho puramente econômico; uma sociedade política, fundada nos partidose no sufrágio; e uma sociedade civil, fundada em direitos de comunicação, associação e movimentos civis. Para os autores essa distinção permitiria superar o tradicional dualismo entre Estado e sociedade, e imprimir, ao mesmo tempo, ênfase à dimensão normativa da vida coletiva, sem que à "colonização do mundo da vida" - tal como apontado por Habermas - seja atribuída a fatalidade da falência da integração social.

Em decorrência, as novas configurações das relações entre Estado e sociedade civil são passíveis de serem pensadas a partir da capacidade de a ordem instituída integrar no processo decisório os múltiplos atores sociais presentes no novo cenário das sociedades contemporâneas, preservando-se as condições para a possibilidade de institucionalização das aspirações normativas desses atores, que dessa forma se transformam em projetos. M as isso, por sua vez, implica que os movimentos sociais transitem de uma prática política defensiva para uma prática política ofensiva, pondo em relevo a necessidade de desenvolverem uma política de influência sobre o Estado para que este, segundo Grau (1996), abra o universo do discurso político a novas identidades e a normas articuladas, de maneira igualitária, na sociedade.

Resgata-se dessa forma a dimensão política do Estado, propondo-se a diferenciação entre a esfera pública e a esfera estatal, ao mesmo tempo que se enfatiza a esfera pública na sua dimensão social, portanto como uma entidade sempre em construção através da dinâmica de os sujeitos coletivos buscarem participar de forma ativa das decisões estatais. A proposição dessa perspectiva, no entanto, confronta-se novamente com a realidade da atual conjuntura marcada pela fragmentação e pulverização social, e conseqüente mudança dos padrões clássicos de representação de interesses dos distintos segmentos sociais, bem como dos mecanismos e dinâmicas de construção das novas identidades sociais como sujeitos coletivos. Noutros termos, da mesma forma que os padrões clássicos de relação entre Estado e sociedade civil sofrem mudanças, altera-se a condição de os sujeitos coletivos se definirem e agirem pautados pelos quesitos normativos envolvidos na cidadania. Em primeiro lugar, pela própria pulverização dos espaços de construção dessa identidade "cidadão", não mais como antes referida única e exclusivamente ao Estado. Em segundo lugar, porque ela implica hoje a reconstrução de redes associativas sob novas condições de igualdade, justiça e liberdade, sendo que os sujeitos coletivos - como segmentos organizados da sociedade - na grande maioria dos casos pautam suas atividades por interesses particularistas; em terceiro lugar, porque em sociedades dos países "emergentes", como éo caso brasileiro, as determinações ditadas pelos constrangimentos econômicos que lhes são impostos pelo processo de globalização, dada a opção política de inserção econômica na nova ordem global dos anos mais recentes, não só agravam a pulverização e a fragmentação social, e portanto a diferenciação social, dificultando assim a criação de redes associativas, como agravam a desigualdade social, radicalizando a segmentação entre os "incluídos", ou passíveis de o serem, e os "excluídos", conforme analisa Fiori (1993), sem qualquer alternativa de inserção social sustentável a médio e longo prazos que não seja através da ação estatal.

Essa situação, por sua vez, contrapõe-se a duas outras forças presentes nas nossas sociedades contemporâneas: uma delas consiste na ten dência e na pressão para que o mercado imponha sua dinâmica e sua lógica como padrão organizador da sociedade, transferindo a responsabilidade da provisão das necessidades sociais para a esfera individual ou familiar, vale dizer, para a esfera privada, como analisa Laurell (2001) ao tratar das reformas das políticas sociais mexicanas no período recente. A segunda força aponta no sentido oposto, e conflui para a perspectiva analítica até o momento apresentada, e diz respeito à demanda e/ou expectativa excessiva sobre esses "novos" sujeitos sociais, para que sua prática esteja voltada para as necessidades e demandas coletivas - a universalidade dos direitos - e não para suas necessidades imediatas e particulares. Como afirmam Kymlicka e N orman (1996): Os teóricos da sociedade civil demandam demasiado das organizações voluntárias quando esperam que sejam a principal escola... da cidadania democrática. Se bem essas associações possam ensinar as virtudes cívicas, esta não é sua razão de ser... Seu objetivo 
é fundamentalmente pôr em prática certos valores e desfrutar de certos bens, eisto pode ter pouco a ver com a promoção da cidadania. Em resumo, verifica-se na atualidade a presença de duas forças opostas e não equivalentes: uma, que enfatiza o âmbito individual ea dimensão privada do plano do mundo da vida, e outra, que enfatiza o âmbito coletivo e a dimensão pública daquele plano. 0 maior ou menor equilíbrio entre ambas certamente é determinado pelo patamar dos níveis de carência presentes na sociedade, e sua dinâmica estará igualmente determinada pelo resgate da dimensão política do Estado.

$M$ arcada não só pela crescente diferenciação e pluralidade de sujeitos e atores sociais com distintos graus na consolidação de sua identidade social, mas concomitantemente pela tensão entre as esferas pública e privada como principal elemento organizador da vida em sociedade, a realidade atual acaba levan do a que a questão dos direitos e da cidadania se apresente nos estudos mais recentes da perspectiva de se buscar compatibilizar gradações e possibilidades distintas de cidadania, uma vez que segundo Vieira (2001) A cidadania, no âmbito deste esfor ço coletivo, não pode mais ser vista como um conjunto de direitos formais, mas como um modo de incorporação de indivíduos e grupos ao contexto social. N esse sentido, a institucionalização de múltiplas cidadanias apontaria para a garantia da justiça e da eqüidade social, que devem levar em conta a heterogeneidade e a multiplicidade das identidades sociais, neste caso enfatizando-se a dimensão cultural, tal como proposto por Kymlicka e N orman (1996).

Outros autores, no entanto, privilegiam a dimensão política da cidadania, como é o caso de Walzer (1992), analisando a sociedade civil da perspectiva do conflito e do enfrentamento de interesses diferenciados. Assim, para o autor, é por permitir o enfrentamento crítico das diversas reivindicações sociais que a sociedade civil desempenha sua tarefa de gerar civilidade, já que o respeito à diversidade e ao pluralismo é que funda o discurso da cidadania.

Traduzida para o caso brasileiro, essa perspectiva pode ser reforçada pela análise apresentada por Nogueira (2001), que, ao partir da perspectiva da política como uma aposta na possibilidade de um diálogo construtivo entre as pessoas, distingue a política dos políticos, a política dos técnicos e a política dos cidadãos. A política dos políticos caracterizando-se por ser universal e permanente, a dos técnicos caracterizando-se pela racionalização e crescentemen- te invadindo o espaço da política, e a política dos cidadãos contrapondo-se às duas anteriores, por aí prevalecerem o debate público e a participação comunitária, neste caso sendo estratégica a educação dos cidadãos no sentido de valorizarem o diálogo ea busca do consenso como meio de resolução de conflitos e de organização da vida.

Por outro lado, Costa (1994) retoma em seus artigos a relação entre as formas de organização de interesses no âmbito da sociedade civil (no seu caso especificamente os movimentos sociais) e a emergência de suas demandas no âmbito da esfera pública, transportando assim para o plano público as "situações-problema" emergentes no âmbito das relações cotidianas, e portanto no âmbito do mundo da vida. Neste caso, à institucional ização de múltiplas cidadanias corresponde o reconhecimento da emergência de múltiplos sujeitos sociais que como grupos de interesse se organizam e se apresentam de formas diversas no âmbito da esfera pública. N esse processo, como aponta o autor, a ação diferenciada desses sujeitos sociais deve consistir "a um só tempo na busca da devolução do caráter privado às esferas privadas e da natureza pública às questões públicas", contrapondo-se exatamente à tendência à "feudalização" dos espaços públicos por determinados grupos de interesses desproporcional mente poderosos que se fazem presentes nos centros decisórios.

\section{Apontamentos sobrea experiência recente da saúde no Brasil}

0 percurso aqui realizado remete a uma questão central, agora referida especificamente às propostas para o setor da saúde como um processo de reformulação institucional do sistema de saúde - o Sistema Ú nico de Saúde - que traz consigo uma nova institucionalidade da participação da sociedade no processo de tomada de decisões políticas através da constituição dos Consel hos de Saúde como instâncias deliberativas.

É abundante a literatura a respeito das experiências dessa modalidade de participação da sociedade no processo de formulação das políticas de saúde, não sendo pertinente portanto apresentar aqui mais um balanço sobre elas, mas simplesmente pontuar al gumas das principais questões que daí emergem tendo em vista a perspectiva aqui adotada. Em resumo, o que está em jogo é se indagar sobre até que ponto e 
em que sentido essa modalidade de participação de distintos segmentos organizados da sociedade nessas instâncias efetivamente avançam no processo de "democratização da democracia", parafrasean do Costa, ou reforçam a presença da dimensão privada e particularista no processo de formulação das políticas de saúde dados os diferentes interesses aí presentes.

Dessa perspectiva ganham destaque algumas características que a dinâmica de tal experiência vem apresentando. A primeira delas diz respeito à evidência da baixa rotatividade dos seus membros, traduzindo provavelmente uma insuficiência do exercício democrático no âmbito da própria sociedade civil, que assim permite que se cristal izem determinados sujeitos sociais como representantes dos distintos interesses econômicos e de demandas a partir de carências aí presentes. A essa baixa densidade do exercício democrático, herança do próprio processo da reforma sanitária brasileira quando os grupos que a lideravam voltaram-se mais para o Estado do que para a sociedade, associase uma concepção de que os Consel hos de Saúde como instâncias do exercício do controle social, tal como incorretamente sempre foi denominado, constituem na sua prática cotidiana instâncias de negociação regidas por uma noção que não diferencia bem comum de interesse comum. De fato, os fundamentos que justificam não só a existência dos Consel hos, mas também a própria dinâmica através da qual se dá a escolha dos seus representantes pressupõem a coincidência entre interesse comum no sentido de que o interesse de cada grupo coincide com o interesse dos demais - e bem comum, no sentido da garantia de que os cidadãos tenham seus interesses igualmente considerados nos processos de tomada de decisão.

A segunda característica diz respeito ao crescente distanciamento entre representadose representantes, ou vice-versa, na exata medida em que a dimensão burocrático-administrativa avança em detrimento da dimensão política propriamente dita: as pautas e discussões travadas naqueles espaços são marcadas por questões operacionais, enão propriamente por negociações entre interesses divergentes ou diferenciados, traduzindo assim o que N ogueira aponta ao distinguir a política dos técnicos da política dos cidadãos. Interessante registrar aqui que nesse sentido os Conselhos constituem uma instância sui generis dado que a política dos políticos tanto no sentido apontado por N ogueira quanto por Cohen eArato aí não se faz presente.
M as retomando-se a dimensão da política dos cidadãos, e resgatando a tendência já apontada anteriormente de no geral se demandar em demasia dos movimentos e organizações sociais quanto a serem a principal escola da cidadania democrática, o fato de essas experiências de controle público através da participação da sociedade nos Consel hos de Saúde ocorrerem num contexto de destituição dos direitos sociais, associado ao altíssimo grau de desigualdade social da nossa realidade, faz com que se acentuem, de um lado, uma maior aproximação entre esse próprio controle e a gestão do Estado, e de outro a proeminência da política dos técnicos sobrea política dos cidadãos, agravando a tendência a uma progressiva tecnificação das políticas sociais, conforme análise de Cohn (2000).

Da mesma forma, ao mesmo tempo que a realidade atual caracteriza-se pela presença de novos espaços de construção de novos sujeitos e identidades sociais, expressando assim a própria fragmentação social da própria realidade, esta é marcada por uma generalização de carências que, vividas e representadas de formas específicas pelos distintos sujeitos coletivos, faz com que a base social das ações coletivas e suas formas de ação se tornem mais próximas, dificultando que suas demandas no processo político de representação de interesses postulem a condição de "interesses general izados" e acabem por prevalecer como "particularismos generalizados", utilizando-se aqui a expressão de autoria de Costa (1994). Dessa perspectiva, a "democratização da democracia" vê-se pouco enriquecida, embora do ponto de vista do arcabouço institucional a implantação do SUS seja ben eficiada ao contar com essas instâncias como um fator a mais exercendo pressão para que ele se efetive. N esse sentido, e recuperando a análise de Paoli e Telles (2000), o que está em jogo é o questionamento sobre se de fato esses espaços de representação, negociação e interlocução efetivamente se constituem em arenas públicas no processo de tomada de decisões.

M as, paradoxalmente, talvez a explicação para a tendência à burocratização e tecnificação da agenda que comanda as pautas das reuniões dessas instâncias resida no próprio fato de nelas a representação de interesses preval ecerem como "particularismos generalizados" enão como "interesses generalizados", o que traduziria que diante da ausência da política dos cidadãos e dos políticos prevaleça a política dos técnicos. $M$ as é exatamente pelo fato de tal hipótese ir ao encontro do forte traço racionalizador que vem 
marcando nesta última década a trajetória intelectual e política dos sujeitos que constituem o campo da Saúde Coletiva no Brasil que é importante se questionar até que ponto a história recente das políticas de saúde no país vem apontando para a construção de um padrão de civilidade em nossa sociedade através da valorização política do confronto entre distintas reivindicações e necessidades de saúde. N outros termos, até que ponto essa trajetória apresenta avanços no sentido de se passar de uma prática política defensiva para uma prática política ofensiva, abrindo o universo do discurso político para novas identidades e normas socialmente articuladas de maneira igualitária. $E$ até que ponto a produção acadêmica tem buscado contemplar essas dimensões sem cair na armadilha de se retomar a antinomia entreEstado e sociedade civil ou, no outro extremo, de se retomar a coincidência entre ambos, confundindo-se 0 público com o estatal.

\section{Referências bibliográficas}

Alexander J 1998. Civil society I, II, III: constructing an empirical concept from normative controversies and historical transformations, pp. 1-19. In J Alexander (org.). Real civil_societies - dilemmas of institutionalization. Sage/ISA, Londres.

Arato A 1995. Ascensão, declínio e reconstrução do conceito de sociedade civil - orientações para novas pesquisas. Revista Brasileira de Ciências Sociais 10(27): 18-27.

Cardoso $R$ 1983. M ovimentos sociais urbanos - um baIanço crítico. In M H Tavares \& B Sorj (org.). Sociedade e política no Brasil pós-64. Ed. Brasiliense, São Paulo.

Cohen J \& Arato A 1992. Civil society and political theory. The MIT Press, Cambridge, M ass.

Cohn A 2000. As políticas sociais no governo FHC. Tempo Social - Revista de Sociologia da USP 11(2):183-198.

Costa S 1994. Esfera pública, redescobrimento da sociedade civil e movimentos sociais no Brasil. N ovos Estudos Cebrap 38:38-52.

Fiori JL 1993. Ajuste, transição e governabilidade: 0 enigma brasileiro, pp. 127-193. In M C Tavares \& JL Fiori. D esajuste global e modernização conservadora. Paz e Terra, Rio de Janeiro,

Fitoussi J-P \& Rosanvallon P 1996. Le nouvel âge des inégalités. Éditions du Seuil, Paris.

Grau NC 1996. A rearticulação das relações Estado-sociedade: em busca de novos significados. Revista do Serviço Público 120(1):113-140.

Kymlicka W \& Norman W 1996. El retorno del ciudadano - una revisión de la producción reciente en teoría de la ciudadanía. Cuadernos del Claeh 20(75):81-112.

Laurell AC 2001. Health reform in M éxico: the promotion of inequality. International Journal of $\mathrm{H}$ ealth Services 31(2):291-391.
Lechner N 1981. El proyecto neoconservador y la democracia. Crítica y U topia. Buenos Aires.

Marshall TH 1963. Cidadania, classe social e status. Zahar Editores, Rio de Janeiro.

M elucci A 1989. Um objetivo para os movimentos sociais? Lua N ova 17:49-66.

M endonça E \& Souto J 2001. Pobreza e desigualdade: re pensando pressupostos. Observatório da Cidadania Relatório 2001/5. Rio de Janeiro, pp. 90-99.

Nogueira M A 2001. Em defesa da política. Ed. Senac, São Paulo.

Offe, C 1989. Trabalho: a categoria sociológica chave, pp. 167-197. In C Offe. Capitalismo desorganizado. Ed. Brasiliense, Rio de Janeiro.

Paoli M.C \& Telles VS 2000. Direitos sociais - conflitos e negociações no Brasil contemporâneo, pp. 103-148. In S Alvarez, E Dagnino \& A Escobar (org.). Cultura e_política nos movimentos sociais latino-americanos novas leituras. Ed. UFM G, Belo H orizonte.

Santos BS 1997. U ma concepção multicultural de direitos humanos. Lua N ova 39:105-124.

Santos WG 1979. Cidadania ejustiça. Ed. Campus, Rio de Janeiro.

Touraine A 1983. Le retour de l'acteur. Payard, Paris.

Vieira L 2001. N otas sobre o conceito de cidadania. Revista Brasileira de Informação Bibliográfica em Ciências Sociais. AN POCS, 51:35-48.

Walzer M 1992. The civil society argument. In C M ouffe (org.). Dimensions of radical democracy. Verso, Londres.

Zaluar A 1997. Exclusão e políticas públicas: dilemas teóricos e alternativas políticas. Revista Brasileira de $\mathrm{C}$ ências Sociais 12(35):29-47. 